side-effects of Abate on the aquatic fauna (see Hamon et al., 1974, for review), and this is currently receiving attention from WHO and also from ecologists, chemists, and toxicologists, from various institutes in Europe, Africa, and North America. Rivers in the area sprayed are being monitored to detect any changes in the fauna that might be caused through insecticidal usage. Furthermore, investigations are being vigorously pursued in various scientific institutes throughout the world to try and develop alternative control methods for black-flies, such as biological control with pathogens and parasites. Unfortunately, however, there are no practical alternative methods that can at present be substituted for insecticidal control.

I hope to have shown that onchocerciasis is a more serious disease in West Africa than was acknowledged by Dr Asibey, and that the authorities involved in the Volta Basin project are fully aware of the possible environmental effects associated with the eradication of river blindness. I am not arguing as to whether this project should have been initiated in West Africa when it was, as much depends on medical and non-medical priorities and whether available technology is considered sufficient to ensure success. However, as it was decided to undertake the project there was (and still is) no alternative but to use insecticides.*

Michael W. Service, Senior Lecturer Department of Medical Entomology Liverpool School of Tropical Medicine Pembroke Place Liverpool, England

* See also the WHO rejoinder published below.-Ed.

\section{References}

Anderson, J., Fulsang, H., Hamilton, P. J. S. \& Marshall T. F. d'E. C. (1974). Studies on onchocerciasis in the United Cameroon Republic. II, Comparison of onchocerciasis in rain-forest and Sudan savanna. Trans. R. Soc. Trop. Med. Hyg., 68(3), pp. 209-21.

AsIBEy, E.O.A. (1975). Black-fly and the environment. Environmental Conservation, 2(1), pp. 25-8.

Buck, A. A. (1974). Global problem of onchocerciasis and its economic impact. Pp. 3-10 in Research and Control of Onchocerciasis in the Western Hemisphere. Pan. Am. Hlth Org., Sci. Publ., No. 298, 154 pp.

DukE, B. O. L. (1974). Clinical manifestations and geographic differences. Pp. 25-9 in Research and Control of Onchocerciasis in the Western Hemisphere. Pan. Am. Hlth Org., Sci. Publ., No. 298, 154 pp.

Duke, B. O. L., Lewis, D. J. \& Moore, P. J. (1966). Onchocerca-Simulium complexes. 1, Transmission of forest and Sudan-savanna strains of Onchocerca volvulus from Cameroon, by Simulium damnosum from various West African bioclimatic zones, Ann. Trop. Med. Parasit., 60(3), pp. 318-36.

Ganley, J. B. \& Biles, J. E. (1973). Prevalence of Onchocerciasis: Visual Impairment and Blindness in Six Villages in the Upper Region of Ghana. World Health Organization document, $\mathrm{PD} / 73.2,38 \mathrm{pp}$. (mimeogr.).

Hamon, J., Quelennec, G., Villars, R., MarR, J. D. M., Stiles, A. R., Gratz, N. G., Parker, J. D. \& Arata, A. A. (1974). Onchocerciasis vectors in the Western Hemisphere. B, Vector control aspects. Pp. 69-84 in Research and Control of Onchocerciasis in the Western Hemisphere. Pan. Am. Hlth Org., Sci. Publ., No. 298, 154 pp.

\title{
Black-fly and the Environment
}

Reference is made to the article under the above title by Dr Emmanuel O. A. Asibey which appeared in Volume 2 No. 1 of Environmental Conservation (being the Spring issue of 1975). Although a preliminary draft of this article was sent to the World Health Organization (WHO) and received extensive comments of a technical nature already in December 1974 , its actual publication was not known until it was recently brought to our attention by a member of our Scientific and Technical Advisory Committee. In the published article there was little reference to these comments, which clarified the raison d'etre of the WHO Onchocerciasis Control Programme and, therefore, it seems inappropriate that acknowledgment be made in it to senior officials of the Organization.

We appreciate Dr Asibey's concern (as Chief Game and Wildlife Officer of Ghana) regarding the environment, but feel it necessary to emphasize that this particular Programme, which is being carried out by WHO at the request of seven countries in the Volta River Basin area, is the subject of environmental monitoring which is perhaps greater than that associated with any former vector-control programme anywhere in the world.

It should be noted that, on environmental grounds, WHO did not utilize DDT as a larvicide, although this chemical has been employed for many years in black-fly control in the project area by the governments concerned. In this respect, it may be pointed out that a great variety of residual insecticides have been used for some time in the area to control agricultural pests. The selection of Abate as the insecticide of choice was made following the screening of approximately 1,000 compounds, and was chosen on the basis of its relatively specific effect on black-fly (Simulium spp.) larvae.

An independent Ecological Panel has approved an aqua- tic monitoring programme which was drawn up with the assistance of hydrobiological experts from around the world, to determine if, or to what extent, environmental changes are being produced by the application of insecticide for black-fly control. This Pancl reviews twice a year the results obtained. Members of the Ecological Panel have visited the Onchocerciasis Control Programme area and there have been no reports of any adverse environmental effects to date. The Institute of Aquatic Biology of the Republic of Ghana, and the ORSTOM Hydrobiological Unit stationed in Bouaké in Ivory Coast, are engaged fulltime in this monitoring programme.

We do not consider it appropriate to comment specifically on a number of points mentioned in the article by Dr Asibey. However, it should be clearly understood that there is as yet no drug which can be used as a prophylactic, and the drugs available to treat those suffering from onchocerciasis are not recommended by experts in this field for mass treatment because of their toxicity and other sideeffects. Furthermore, when a suitable drug is developed, chemotherapeutic measures will be undertaken concomitantly with black-fly control.*

J. D. M. MARR, Entomologist/Biologist Onchocerciasis Control Programme World Health Organization

Avenue Appia

1211 Geneva 27

Switzerland.

* See also Dr Michael W. Service's comments in his 'Black-flies and the Environment: A Reply to Dr Asibey' published on pp. 115-6 of this issue. Dr Asibey, having seen both these communications engendered by his original paper, reserves the right to reply in due course.-Ed. 